\title{
Measles on the Rise in the U.S despite its preventable Nature, a Call to Manage the Epidemic
}

\author{
Marco Taboada. Marco ${ }^{1}$, Singh. Shanpreet ${ }^{1}$, Kapella Mshigeni. Salome ${ }^{2^{*}}$, Okpala. PaulChris ${ }^{3}$ \\ ${ }^{1}$ California State University San Bernardino \\ ${ }^{2}$ Department of Health Science and Human Ecology \\ ${ }^{3}$ College of Natural Science, California
}

\begin{abstract}
*Corresponding Author: Kapella Mshigeni. Salome, Department of Health Science and Human Ecology,
\end{abstract} Email: Salome.Mshigeni@csusb.edu

\begin{abstract}
Introduction: Despite the advancements in public health and the effectiveness of vaccinations to eliminate diseases that cause harm to the population, vaccine preventable diseases are still spreading in our communities.
\end{abstract}

Methods: This exploratory study focused on a systematic review of measles, a disease that resulted into an epidemic of cases in the U.S. in 2019.

Results: Possible factors that may contribute to parental decisions not to vaccinate their children are: perceived susceptibility of their children to illness, children's young age, and parents' personal health beliefs, among others.

Conclusions: Refusal to vaccinations is a concerning public health issue that needs to be revisited as our communities are currently experiencing preventable disease occurrences. Managing the population of unvaccinated individuals remains a challenge for public health professionals. A call for strict laws is needed to ensure vaccination compliance practices are followed. Also, there is a need to educate the public about the importance of vaccines that prevent diseases, as they have immeasurably improved the quality of life for many.

Keywords: Vaccination, Epidemic, Measles, Management.

\section{INTRODUCTION}

In the midst of the 21st century, the United States is still struggling with vaccine preventable diseases (VPDs) such as measles. Although there have been improvements to immunization practices since the inception of the first smallpox vaccine, which was proven to be a reliable method to prevent diseases such as polio and measles in 1955 and 1963 respectively, as a community, we are still challenged with understanding how effectively vaccinations can prevent infectious diseases and prolong lives (California Department of Public Health $[\mathrm{CH}$ DP], 2015).The discovery of vaccinations advanced public health efforts forward causing diseases that once ravaged communities to no longer be a health issue.

Successfully, in the year 2000 , polio vaccine was no longer recommended in the United States since there had been no cases of the disease in the country since 1979 (Centers for
Disease Control and Prevention [CDC], 2018a). However, vaccine preventable diseases such as pertussis $(18,975$ cases in 2017 and 13,439 cases in 2018) and chicken pox are still common in the United States with several children experiencing them (CDC, 2018a).

These contradiction incidents tend to come often from individuals forgoing immunizations for unknown reasons (CDC, 2019e; CDC, 2018a; CDC, 2016a). Further, because of an increasing number of individuals refusing vaccinations, measles may no longer be eradicated in the U.S. as once declared.

From January 1 to November 7, 2019 the U.S. has experienced a total of 1,261 individual confirmed cases of measles in 31 states, the highest number reported since the disease was eliminated in 2000 (CDC, 2019a; U.S. Health News, 2019). Further, epidemiological predictions of cases have been exceeded since the 2019 outbreak (1,261 and counting) has 
surpassed that of 2014 with 667 cases of measles (CDC, 2019a). If not properly treated the measles virus can lead to deadly complications, however there have been no reports of any deaths resulting from the recent outbreaks (CDC, 2019a). Measles can potentially lead to pneumonia, brain damage, deafness, and in rare cases death (CDC, 2019a). Hence, the CDC continues to warn public health officials that if we stop vaccinating, even those rare cases we have had in the U.S. could rapidly expand into hundreds of thousands of cases (CDC, 2019a). Strong policies that will ensure proper management of vaccination practices are needed to prevent such epidemics from reoccurring in the future.

Each disease works in different ways, shapes, forms, and it can be challenging to envision a clear forecast of some epidemics. However, a disease like measles has a defined vaccine that remains constant every year, yet some people refuse to vaccinate against it. Vaccination procedures for MMR have varied over the years, whereby some people received only one dose while others received multiple doses. However, the CDC has clarified that 2 doses of the measles vaccine is needed to ensure a $97 \%$ effectiveness level in comparison to one dose that is reported to be $93 \%$ effective (CDC, 2019a). Ultimately, the goal of public health work is to prevent diseases through immunization practices rather than treating people when diseases are already out of control. Recent challenges to control measles in the 1960s opened a door for immunization laws in the U.S. whereby states required children to be vaccinated before entering school unless justified by their pediatrician (AAFP, 2014; Omer, Salmon, Orenstein, DeHart, \& Halsey, 2009).

\section{LITERATURE REVIEW}

In the U.S., measles should have been put behind us a long time ago because of vaccine practices that have been present for over fifty years, however this is not the case as the media is providing weekly updates on the number of outbreaks taking place in 2019 among 31 states (WHO, 2019; CDC, 2019a).

According to the CDC, the Measles, Mumps, and Rubella vaccine (MMR) rate is currently 91.9\% among children ages 19 - 35 months (2019a). This is understandable because due to preexisting medical conditions, some individuals may not be able to receive vaccinations at a recommended schedule (CDC, 2017a). Even with such a high vaccination rate for MMR $(91.9 \%)$, those who refuse to vaccinate their children put others at greater risk of acquiring the disease and make it difficult for public health professionals to manage the epidemic. In addition, due to modern travel patterns, the severity of the epidemic is expected to grow and expand to more states as international travelers may bring measles into the U.S. (CDC, 2019a).

Thus, the presence of herd immunity is one of the indirect benefit of vaccinations which helps protect unvaccinated populations in each community (Kim, Johnstone, \& Loeb, 2011). It is understandable that certain populations may not be able to get certain vaccines, such as infants, the elderly, people with certain allergies, and people with an immune-suppressing disease like HIV or cancer but achieving a vaccination rate of $75 \%-95 \%$ is enough to provide indirect protection from vaccines to these population (Watson, 2018). For herd immunity to work and protect many people from getting the diseases, a very high percentage of people in a certain area needs to be vaccinated. The more contagious a disease is, the higher the percentage a community needs to achieve herd immunity. For public health efforts to successfully provide herd immunity against measles, $93 \%$ to $95 \%$ of people should be vaccinated in the community (Kim, et al., 2011). Particularly, about 95 out of every 100 people in a community need to get vaccinated to prevent measles (Watson, 2018). When fewer people get vaccinated, the diseases that were once controlled can occur again, and this may hinder public health prevention efforts to manage and control the disease. The literature suggests that some types of vaccinations are better at producing herd immunity than others, and the MMR vaccine is effective at preventing measles if taken at the two recommended dose time (Watson, 2018).

In 2015, there was an outbreak of measles in Disneyland theme park in California whereby there was one unvaccinated patient aged 11years-old with an onset symptom of measles i.e. rash (CDC, 2015a). The patient was among the few unvaccinated children who were exposed due to their vaccination status. In February 11, 2015; the CDC further confirmed 125 cases of measles outbreaks in Disneyland California during the December 28, 2015 - February 8, 2015 time frame. One hundred and ten patients were from California and 49 of those cases were confirmed to be unvaccinated individuals (CDC, 2015a). During this particular measles outbreak from 2015, 30 cases (out of the 49) were 
situations where people intentionally did not vaccinate due to their own personal beliefs whereby 18 of them were unvaccinated children.

Such actions draw the attention of public health professionals to explore why some parents refuse to vaccinate their children despite the availability of VPDs. Upon gaining an understanding of factors influencing why some people may choose not to vaccinate, public health efforts will be geared towards the provision of evidence-based education that will help people understand the importance of vaccinations.

\section{Methodology}

This systematic review has been conducted to provide insights into why some people choose not to vaccinate against Measles, a disease that has resulted into an epidemic in the U.S. in2019.This study design allows us to look at numerous studies and provide recommendations for public health professional on how to go about educating the public about the importance of vaccinations. Further, systematic review is a high form of evidence that informs policies set by different state and healthcare agencies in requiring parents to vaccinate all school age children (Cochrane Collaboration, 2011).

In this study we aimed to identify, evaluate, and integrate relevant studies that address why some people refuse to vaccinate against preventable diseases such as measles (Randolph, 2009). We analyzed to see if there has been progress in finding the reason(s) why people choose to vaccinate or not vaccinate against common diseases (Baumeister \& Leary, 1997; Green, Johnson, \& Adams 2006).

We conducted an extensive search of libraries and various databases (i.e. PubMed, EBSCO, SCOPUS, Cochrane Library, APA PsycINFO and Grey literature) looking for studies that focused on measles conducted between 2005 to 2018 on individuals who refused to vaccinate. We found twenty studies that looked at the reasons why people chose to vaccinate or not vaccinate against measles and examined for common themes. Further, we searched for factors in these studies that led to individual's refusal to vaccinate against measles. As Saldaña (2013) once stressed, creating major themes of possible reported reasons as to why cases were not vaccinated is a good place to start with. Additionally, we surveyed policy documents of various public health agencies in a large populated state such as California regarding the awareness of vaccine preventable diseases.

\section{Study Results}

As of November 7, 2019; 31 states have a total of 1,261 confirmed cases of measles in the fall 2019 including: Alaska; Arizona, California, Colorado, Connecticut, Florida, Georgia, Hawaii, Idaho, Illinois, Indiana, Iowa, Kentucky, Maine, Maryland, Massachusetts, Michigan, Missouri, New Mexico, Nevada, New Hampshire, New Jersey, New York, Ohio, Oklahoma, Oregon, Pennsylvania, Texas, Tennessee, Virginia, and Washington (CDC, 2019a) and the numbers are expected to grow (CDC, 2019a). It is noted that the largest numbers are present in New York City, where over 654 cases have been documented, making it the city's worst measles outbreak in 30 years (New York Health, 2019; Health News, 2019). In Washington State, the number of confirmed cases were 86, from Clark and King counties (Washington State Department of Health, 2019).

In Oregon, there were a total of 22 confirmed cases of measles spread in 4 counties: Clackamas; Columbia, Marion, and Multinomah (Oregon Health Authority, 2019). In the neighboring state of New Jersey, there has been 19 confirmed cases of measles (State of New Jersey Department of Health, 2019). In Michigan, there were confirmed 46 cases of measles statewide (Michigan Department of Health \& Human Services, 2019). In other states such as California, the total number is 56 confirmed cases of measles (CDC, 2019a). According to Dr. Amesh Adlja, an infectious disease expert from John Hopkins Center for Health security, "the U.S. is now fighting a disease in 2019 that should have been off the table in the 1960s, as a result of the development of the vaccine" (Health News, 2019).

Back in 2015, there were 110 reported cases of measles in California patients that were related to the outbreak at the Disneyland theme park and 12 of those patients were too young to receive the vaccinations for measles (CDC, 2015a) Forty-nine patients were found to be unvaccinated and 28 were intentionally unvaccinated due to personal beliefs (CDC, 2015a). Eighteen of the 28 unvaccinated patients were children under 18 years and 10 were adults (CDC, 2015a). The disease outbreak originated from Disneyland theme parks, with seven other states reporting that it had cases of people who visited the theme park during the outbreak 
period (CDC, 2015a). Given such a large population it is important to remember that large clusters of people can be a detriment when it comes to VPDs. With public theme parks receiving international visitors daily, the risk further increases and exposes many vulnerable populations. Importantly, those unable to receive vaccinations face a greater risk when those who can receive vaccines do not participate in strengthening herd immunity (CDC, 2015a).

\section{DISCUSSION}

Our research question intended to explore why some people refuse to vaccinate despite the availability of vaccines. Currently, many people are forgoing recommended vaccinations and as a result, society is now experiencing an epidemic. There have been many exceptions that have resulted in weakening our herd immunity in the community. There is a need to create stricter vaccination compliance rules that must be followed i.e. healthcare professionals, school districts, parents, and city \& county offices. As suggested in the literature, for measles to achieve herd immunity, at least $93 \%$ to $95 \%$ of the population should be vaccinated against the disease (Kim, et al., 2011).

\subsection{Study Limitations}

Although this study was conducted judiciously, we are aware of its limitations. First, different VPDs had different levels of details in relation to specific reasons as to why some people refuse to vaccinate. Hence, there is lack of consistency in the way that the individual articles in the literature present their findings on this matter. Second, this paper consists of a review of secondary data, by looking at existing studies that have been conducted as opposed to primary data collection. We mainly reviewed articles and reports on cases of the measles that have been reported within the past five years to 2018 and examined the reasons as to why some people refuse to vaccinate. The use of secondary data limits our knowledge of factors that the study investigators could have explored directly from the field, given the means to reach a representative population of people residing in the U.S. who chose not to vaccinate.

\subsection{Study Recommendations}

One of the major recommendations of this study is to reorganize the surveillance of VPDs and allow for more factors to be examined. The CDC has a surveillance activity manual presented on its website that coincides with 52 jurisdiction health departments (CDC, 2017b). Collaboration with medical providers, school health districts, and family's needs to be implemented in order to closely monitor and follow up on unnecessary gaps in vaccination practices. Altering standards of tracking vaccination status to allow for further analysis of individuals as well as communities would be beneficial. With better tracking of vaccination status and its justification is imperative for public health professionals to conduct studies that will provide an understanding as to why some people refuse to vaccinate. Improved policies that can be initiated at the county, city, and state levels are needed to effectively manage the practices of vaccination compliance.

Without a doubt, the CDC must continue to emphasize the importance of receiving vaccinations so that the entire population is protected, since the ultimate goal is to strengthen and maintain our communities' herd immunity so that individuals with compromised immune systems are protected i.e. cancer and HIV patients (CDC, 2018b). Possibly, those who are not vaccinated interfere with herd immunity, resulting in the spread of communicable diseases. Further, enforcing strict policies to ensure timely vaccinations is highly recommended whereby health professionals, unified school district systems, and health departments should work collaboratively to help people follow the law.

Certain ethnic groups were perceived to be at a higher risk of receiving vaccines that could cause certain complications. We recommend that scientific research is done to understand these disparities and provide further education opportunities to groups that show higher risks to VPDs. By doing so, the chance of complications will less likely occur if proper education is available to high risk groups of people. The $\mathrm{CDC}$ recommends measles vaccinations as the disease is very contagious, spreading through air by a cough or sneeze from an infected person (CDC, 2019a). The good news is that the vaccine is very effective, and it is reported to prevent not only measles but also mumps and rubella at $97 \%$ if two doses are completed and at 93\% if one dose is completed (CDC, 2019a).

\section{CONClusion}

Vaccinations have immeasurably improved our quality of life and prolonged the typical human lifespan (WHO, 2019). Vaccinations have led to the eradication of diseases such as smallpox and near elimination of diseases such as diphtheria 
and polio (CDC, 2017a). The increasing rate of parents who refuse or delay recommended vaccines for their children is a growing problem, resulting in resurgence of vaccine preventable diseases such as measles (Williams, 2014). Some people have chosen not to believe in science due to the fear that the vaccine may cause autism due to prolonged research that has been carried by anti-vaccination groups (Kaye, Melero-Montes, \& Jick, 2001). Thus, the number of school aged children with exemptions from immunizations are at an increased risk of catching measles and can infect others who may be too young or sick to vaccinate due to medical conditions (Omer, et al., 2009). Thus, the government should get more people vaccinated by revising rules and laws that will scrutinize exemption issued by healthcare professionals. Also, educating communities about vaccinations benefits will potentially increase compliance practices and prevent future epidemics.

In public health work, vaccines are the most effective prevention tools available to clinicians, but their success depends on community compliance for coverage. Hence refusal to vaccination is a concerning public health issue that needs to be revisited. In attempting to address vaccination refusal, it is important to note that some parents are just trying to do what "they think" is best for their children or their own health (Glanz, Kraus, \& Daley, 2015). However, when we experience trending epidemics such as measles, it is a window of opportunity for healthcare providers not only to inform but also educate the parents as well as the public about the importance of conforming to vaccination practices in order to control the spread of communicable diseases. The American Academy of Pediatrics suggests that, instead of turning away patients who are not compliant with vaccinations, addressing vaccine refusal while respectfully understanding parental concerns is a chance to discuss the risks of nonvaccinating practices (Omer, Salmon, \& Orenstein, 2009).

This study is important because of current epidemics happening in the U.S. today such as measles. Vaccines have saved millions of lives each year and they are the most cost-effective medicine and public health greatest intervention ever developed. Immunizations led to the eradication of smallpox, near elimination of polio, and approximately $74 \%$ reduction in childhood death from measles (Bill \& Melinda Gates, n.d.). Although there are many factors that may contribute to parental decision not to vaccinate their children, the overall benefits outweigh the risks and concerns that people may have when it comes to negative side effects. Staying in touch with one's medical provider is the best practice for a healthier society.

\section{REFERENCES}

[1] American Academy of Family Physicians (2014). Pertussis Is Latest Disease Outbreak Concern in United States. Retrieved 14 April 2019, from: https://www.aafp.org/news/healthof-the-public/20140625pertussi s.html

[2] Baumeister, R. F., \& Leary, M. R. (1997). Writing narrative literature reviews. Review of General Psychol ogy, 3, 311-320.

[3] Bill and Melinda Gates Foundation. Vaccine Delivery. Retrieved from https://www.gatesf oundat ion.org/ what-we-do/global-developmen $\mathrm{t} /$ vaccine-delivery

[4] California Department of Public Health (2015) Vaccine - Preventable Disease Surveillance in California. Retrieved 16 April 2019, from: https://www.cdph.ca.gov/Programs/CID/DCD C/CDPH\%20Document\%20Library/VPD-An nualReport2015.pdf

[5] Center for Disease Control and Prevention (2019a). Measles (Rubeola): Measles Cases and https://www.cdc.gov/measles/casesoutbreaks.html

[6] Center for Disease Control and Prevention (2019b). Influenza (Flu): 2018 - 2019 U.S. Flu Season: Preli min ary Burden Estimates. Retrieved on April 20, 2019 from: https://www. cdc.gov/flu/about/burde $\mathrm{n} / \mathrm{pr}$ eliminary-in-seaso n-estimates.htm?rel=0

[7] Center for Disease Control and Prevention (2019e). 2018 Provisional Pertussis Surveill ance Report: repo rted Pertussis Inci dence and Cases. Retrieved on June 8th, 2019 from: https://www.cdc.gov/pertussi s/dow nloads/pert uss-surv-report-2018-508.pdf

[8] Center for Disease Control and Prevention (2018a). Manual for the Surveillance of Vaccine Preventable Diseases - Chapter 17: Varicella. Retrieved on June 5th, 2019 from: https://www.c dc.gov/vacc ines/pubs /surv-ma nual/chpt17-var icella.html

[9] Center for Disease Control and Prevention (2018b). Vaccines \& Immunizations: Why Immunize? Retriev ed on October $1^{\text {st }}, 2019$ from:https://www.cdc.gov/vaccines/vac-gen/ why.htm

[10] Center for Disease Control and Prevention (2017a). Polio | U.S. Polio Elimination | CDC. Retrieved on April 9, 2019 from: https://www .cdc.gov/polio /us/

[11] Center for Disease Control and Prevention. (2017b). Manual for the Surveillance of Vacc 
ine-Preventable Diseases. Retrieved May 29, 2019, from: https://www.c dc.gov/vacc ines /pubs/surv-manual/chpt23-natl-surv-vpd.html

[12] Center for Disease Control and Prevention (201 6a). FastStats. Retrieved on April 9, 2019 from: https://www.cdc.gov/nchs/fastats/immunizeht m

[13] Center for Disease Control and Prevention (2015a). Measles Outbreak - California, Decem ber 2014-February 2015. Retrieved on April 9, 2019 from: https://www.cdc.gov/mmwr/previe w/mmwrhtml/mm640 6a5.htm

[14] Glanz, J. M., Kraus, C. R., \& Daley, M. F. (2015). Addressing Parental Vaccine Concerns: Engagement, Balance, and Timing. Retrieved on April 5th, 2019 from: http://journals.plos.or $\mathrm{g} /$ plosbiology/articlee?id=10.1371/journal.pbio .100 2227\#references

[15] Green, B. N., Johnson, C. D., \& Adams, A. (2006). Writing narrative literature reviews for peer reviewed journals: Secrets of the trade. Journal of Chiropractic Medicine, 5, 101-117.

[16] Gust A, Kennedy A, \& Shui I (2005). Parent attitudes toward immunizations and healthcare providers the role of information. American Journal of Preventive Medicine. 29(2):105-112.

[17] Higgins J. P.T., \& Green S. (editors) (2011). Cochrane Handbook for Systematic Reviews of Interventions Version 5.1.0. The Cochrane Collaboration.

[18] Health News: U.S. Measles cases hit highest level since eradication in 2000. Retrieved on Apr il26,2019from:https://www.reuters.com/article/u s-usa-measles/u-s-measles-cases-at-highe st-sin ce-elimination-in-2000-cdc-idUSKCN1S0 2L 2

[19] Kaye, Melero-Motes, \& Jick, (2001). Mumps, measles, and rubella vaccine and the incidence of autism recorded by general practitioners: a time trend analysis, British Medical Journal, 322(7284), 460-463. On

[20] Kim, T., Johnstone, J., Loeb, M (2011). Vaccine herd effect, Scandinavian Journal of Infectious Diseases, 43(9), 683-689.

[21] Michigan Department of Health \& Human Services (2019). 2019 Michigan Measles Outbreak Information. Retrieved on April 19, 2019 from:https://www.michigan.gov/mdhhs/ 0,585,7-339-73971_4911_4914_68359-49298 $1--, 00 . h t m l$
[22] New York Health (2019). Measles: Recent Outbreak in Brooklyn and Queens. Retrieved on April 29, 2019 from: https://www1.nyc.gov/ site/doh/health/health-topics/measles.page

[23] Omer, Salmon, Orenstein, DeHart, \& Halsey (2009). Vaccine Refusal, Mandatory Immuniza tions, and the Risks of Vaccine-Preventable Diseases. The New England Journal of Medici ne, 360:1981-1988.

[24] Oregon Health Authority (2019). Measles/ Rubeola (vaccine-preventable) - 2019 Measles Information. Retrieved on April 25, 2019 from: https://www.oregon.gov/oha/PH/DISEASESCO NDITIONS/DISEASE SAZ/Pages/measles.aspx

[25] Randolph, J. J. (2009). A guide to writing the dissertation literature review. Practical Assessment, Resear ch \& Evaluation, 14, 1-13

[26] Saldaña, J. (2013). The coding manual for Qualitative Researchers, Sage Publications, Thousand Oaks, CA

[27] State of New Jersey Department of Health (2019). Communicable Disease Service Measles: April 2019 Potential Measles Exposure in Monmouth County Related to Highly Suspect Case. Retrieved on April 25, 2019 from: https://www.state.nj.us/health/cd /to pics/measles.shtml

[28] Washington State Department of Health, 2019. Measles Outbreak 2019: Measles outbreak in Washington State. Retrieved on April 25, 2019 from:https://www.doh.wa.gov/YouandYourFa mily/IllnessandDisease

/Measles/MeaslesOutbreak

[29] Watson, S. (2018, December 03). What's Herd Immunity, and How Does It Protect Us? Retrieved June 4, 2019, from https://www.web $\mathrm{md} . \mathrm{com} /$ vaccines/news/20181130/what-herdimmunity-and-how-does-it-protect-us

[30] Williams, S. E. (2014). What are the factors that contribute to parental vaccine-hesitancy and what can we do about it? Retrieved on April 20, 2019 from: https://www.ncbi.nlm.n ih.gov/pmc/articles/PMC4977453/

[31] World Health Organization (2019). Immunizati ons, Vaccines, and Biologicals: Measles. Retrieved on April 25, 2019 from: https://www. who.int/immunization/diseases/measles/en/

Citation: Marco Taboada. Marco, et al, Measles on the Rise in the U.S despite its preventable Nature, a Call to Manage the Epidemic.ARC Journal of Public Health and Community Medicine.2019; 4(2):1-6. DOI: dx.doi. org/10.20431/2456-0596.0402001.

Copyright: () 2019 Authors. This is an open-access article distributed under the terms of the Creative Commons Attribution License, which permits unrestricted use, distribution, and reproduction in any medium, provided the original author and source are credited. 